\title{
Phosphate removal from water using freshly formed Fe-Mn binary oxide: Adsorption behaviors and mechanisms
}

\author{
Jianbo Lu ${ }^{\mathrm{a}, \mathrm{b}, \mathrm{c}}$, Huijuan Liu ${ }^{\mathrm{a}, *}, \mathrm{Xu}_{\text {Zhao }}{ }^{\mathrm{a}}$, William Jefferson ${ }^{\mathrm{a}}$, Fang Cheng ${ }^{\mathrm{b}, \mathrm{c}}$, Jiuhui Qu ${ }^{\mathrm{a}}$ \\ ${ }^{a}$ Key Laboratory of Aquatic Science and Technology, Research Center for Eco-Environmental Sciences, Chinese Academy of Sciences, Beijing 100085, China \\ b School of Environmental and Municipal Engineering, Tianjin Chengjian University, Tianjin 300384, China \\ c Tianjin Key Laboratory of Aquatic Science and Technology, Tianjin Chengjian University, Tianjin 300384, China
}

\section{H I G H L I G H T S}

- A freshly formed Fe-Mn binary oxide (FMBO) suspension was synthesized.

- FMBO had different physicochemical properties from the mixture of Fe and Mn oxides.

- Phosphate adsorption followed trend FMBO $>$ mixed oxide $>$ ferric oxide at pH 3-10.

- The mechanism of phosphate adsorption on FMBO was clarified.

\section{A R T I C L E I N F O}

\section{Article history:}

Received 23 November 2013

Received in revised form 7 April 2014

Accepted 12 April 2014

Available online 20 April 2014

\section{Keywords:}

Ferric oxide

Manganese oxide

Binary oxide

Phosphate

Adsorption

\section{G R A P H I C A L A B S T R A C T}

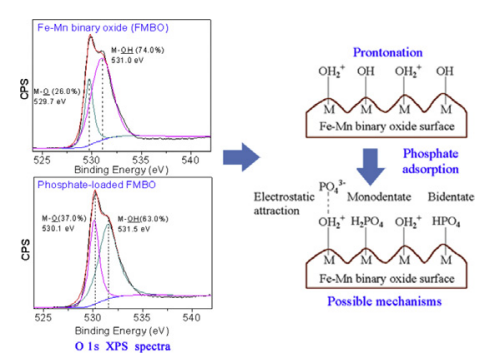

\begin{abstract}
A B S T R A C T
Freshly formed metal oxide suspensions usually have high reactivity and are easy to achieve in-situ preparation and dosing in water treatment. In this study, a freshly formed Fe-Mn binary oxide (FMBO) suspension was prepared for phosphate removal using simultaneous oxidation and coprecipitation method. FMBO was characterized by SEM, TEM, XRD and zeta potential and compared with the mixture of ferric oxide and manganese oxides (FMMO), hydrous ferric oxide (HFO) and hydrous manganese oxide (HMO). Results indicated that ferric oxide was relatively enriched on the surface of nanostructured binary oxide, resulting in its $\mathrm{pH}_{\mathrm{ZPC}}$ and XRD pattern close to HFO. At $\mathrm{pH} 3-10$, phosphate removals followed trend: FMBO > FMMO > HFO > HMO. The pseudo-second-order kinetics model provided a better fit for phosphate adsorption onto FMBO, indicating that chemisorption may play a dominant role. The maximum adsorption capacity estimated from the Langmuir equation was $0.223 \mathrm{~mol}-\mathrm{P} / \mathrm{mol}-\mathrm{Fe}$ at $\mathrm{pH}$ 5.0. The competition effects of coexisting substances such as sulfate, bicarbonate, silicate and DOC on phosphate adsorption using FMBO were not significant. Phosphate adsorption onto FMBO could be attributed to electrostatic interaction and replacement of surface hydroxyl groups via formation of monodentate and bidentate complexes.
\end{abstract}

(c) 2014 Elsevier B.V. All rights reserved.

\section{Introduction}

Phosphate is an essential nutrient element for living organisms. However, in aquatic environments, its excessively high concentration may deteriorate ecosystems and bring about subsequent

\footnotetext{
* Corresponding author. Tel.: +86 10 62849160; fax: +86 1062849160.

E-mail address: hjliu@rcees.ac.cn (H. Liu).
}

water quality problems [1]. Therefore, it is crucial for researchers to develop effective technologies for phosphate removal in water and wastewater treatment systems. Among various available technologies for decontamination of phosphate, the adsorption method is relatively simple, economical, and highly efficient $[2,3]$.

In adsorption process, metal (hydr) oxides adsorbents such as iron, aluminum and manganese (hydr) oxides are widely used in water and wastewater treatments $[4,5]$. In natural waters, these metal oxides are omnipresent and they are also found in 
combination with each other to form composite oxides [6,7], which may display physicochemical properties different from those of their single component oxides. Thus the development of composite oxides adsorbents containing two (or more) different metal oxides has drawn great attention in recent years [7-12]. In these studies, researchers only concentrate on adsorptive characteristics of relatively well-defined solid oxides for pollutants. However, in aquatic environments when these oxides are freshly formed, they often take on hydrous and amorphous forms with bulk surface properties distinctly different from aged solid oxides [3,13]. Further, adsorptive capability of aged solid oxides might decrease due to drying preparations. In particular, these solid oxides are mostly powdery, making their direct engineering applications difficult. By contrast, freshly formed oxide suspensions can maintain high surface reactivity and adsorptive capability [14]. When utilized as adsorbents in water treatment, freshly formed oxide suspensions are easy to prepare in situ, dose in the water to be treated and subsequently rapid adsorptive reaction occurs. This is very favorable for its engineering applications in the treatment of water or wastewater, especially the remediation of phosphate-contaminated water body. Among various oxides, iron and manganese (hydr) oxides are well known due to their affinity towards phosphate $[4,15]$. However, until now, very little is known about the adsorption behaviors of phosphate on freshly formed Fe-Mn binary oxide.

Thus, the objectives of the current study are to: (1) evaluate physicochemical properties of different freshly formed oxide suspensions (FMBO, FMMO, HFO and HMO) via determination of particle size distribution, zeta potential, X-ray diffraction (XRD) and other analytic techniques; (2) illustrate the characteristics of phosphate adsorption on freshly formed FMBO such as pH effects, adsorption kinetics, isotherms and effect of coexisting substances through batch experiments; and (3) propose the dominant mechanisms involved in phosphate removal by freshly formed FMBO using Fourier transform infrared spectroscopy (FTIR) and X-ray photoelectron spectroscopy (XPS) techniques.

\section{Materials and methods}

\subsection{Materials}

In this study, with the exception of humic acid purchased from Sigma-Aldrich Corporation (USA), all other chemicals were purchased from Sinopharm Chemical Reagent Company (China) and were of analytical reagent grade. The phosphate standard stock solution was made from anhydrous potassium dihydrogen orthophosphate $\left(\mathrm{KH}_{2} \mathrm{PO}_{4}\right)$. All solutions were prepared using deionized water.

\subsection{Preparation of freshly formed oxides}

Four kinds of freshly formed oxide suspensions were prepared in the current study, which included FMBO, FMMO, HFO and HMO. The FMBO was freshly prepared using $\mathrm{FeSO}_{4}$ reaction with $\mathrm{KMnO}_{4}$ according to the molar ratio of 3:1. The preparation procedure of FMBO was as follows: potassium permanganate $\left(\mathrm{KMnO}_{4}\right)$ was dissolved in $100 \mathrm{~mL}$ of deionized water; ferrous sulfate heptahydrate $\left(\mathrm{FeSO}_{4} \cdot 7 \mathrm{H}_{2} \mathrm{O}\right)$ was dissolved in another $100 \mathrm{~mL}$ of deionized water. Under vigorous magnetic stirring, the solution of $\mathrm{FeSO}_{4}$ was added into the $\mathrm{KMnO}_{4}$ solution, and meanwhile $5 \mathrm{M} \mathrm{NaOH}$ solution was added dropwise to keep the solution $\mathrm{pH}$ in the range of 7-8. The $\mathrm{HFO}$ was made from $\mathrm{Fe}_{2}\left(\mathrm{SO}_{4}\right)_{3}$. After ferric sulfate was dissolved in $200 \mathrm{~mL}$ of deionized water, the solution $\mathrm{pH}$ was adjusted to 7-8 under magnetic stirring. The $\mathrm{HMO}$ was synthesized using $\mathrm{MnSO}_{4}$ and $\mathrm{KMnO}_{4}$ with a molar ratio of $3: 2$. The $\mathrm{pH}$ of final solutions also ranged between 7 and 8 using $\mathrm{NaOH}$ solution adjustment.
Moreover, the $\mathrm{pH}$ values of three formed suspensions were continuously adjusted for $0.5 \mathrm{~h}$ until the $\mathrm{pH}$ value was close to stability. The above-mentioned individual HFO and HMO suspensions were mixed physically according to the Fe/Mn molar ratio of 3:1, and the obtained mixture was designated as FMMO. Prior to each set of adsorption experiments, the suspensions of FMBO, HFO, FMMO and HMO were all freshly prepared and agitated gently using magnetic stirrers to keep metal oxide concentrations as uniform as possible.

\subsection{Adsorption experiments}

All batch adsorption experiments were conducted at room temperature $\left(25 \pm 2{ }^{\circ} \mathrm{C}\right)$ with a constant ionic strength of $0.01 \mathrm{M} \mathrm{NaCl}$. The $\mathrm{pH}$ values of solutions were adjusted by adding hydrochloric acid and sodium hydroxide. The $\mathrm{pH}$ measurements were carried out using an Orion $\mathrm{pH}$ meter (Orion 3 star, Thermo Scientific, USA). Results of kinetics experiment showed that the equilibrium of phosphate adsorption was reached within $1 \mathrm{~h}$. Thus with the exception of adsorption kinetics experiments, adsorption tests were performed for $1 \mathrm{~h}$ under gentle magnetic stirring conditions. Samples were immediately filtrated through $0.45 \mu \mathrm{m}$ filter membrane to analyze phosphate concentrations in the filtrate. The phosphate concentrations were measured by a UV-VIS spectrophotometer (Hitachi U3010, Japan) according to a standard method (the ascorbic acid-molybdate blue method). If necessary, the concentrations of Fe and Mn in filtrates were also determined using an inductively coupled plasmaoptical emission spectrometer (ICP-OES700, Agilent Technologies, USA).

Adsorption kinetics experiments were performed at $\mathrm{pH} 7.0$ in a $1 \mathrm{~L}$ beaker. Under magnetic agitation, the FMBO, HFO, FMMO and HMO suspensions were respectively added into $1 \mathrm{~L}$ solutions containing a phosphate concentration of $2.6 \mathrm{mg} / \mathrm{L}$. The iron concentrations of final formed solutions were $0.24 \mathrm{mM}$ for FMBO, HFO and FMMO adsorption tests whereas the manganese concentration was $0.24 \mathrm{mM}$ for HMO adsorption test. At a fixed preselected time interval, $10 \mathrm{~mL}$ sample was taken using a pipette and filtered immediately using a $0.45 \mu \mathrm{m}$ filter membrane for the measurement of phosphate concentration in the filtrate.

The $\mathrm{pH}$ effect experiments were conducted in $500 \mathrm{~mL}$ solutions applying a phosphate concentration of $1.1 \mathrm{mg} / \mathrm{L}$. The solution $\mathrm{pH}$ ranged from 3 to 10 . The iron concentrations were all $0.12 \mathrm{mM}$ for FMBO, HFO and FMMO adsorption tests whereas the manganese concentration was $0.12 \mathrm{mM}$ as for HMO adsorption test.

In adsorption isotherms experiments, $500 \mathrm{~mL}$ solutions were prepared in which phosphate concentrations varied from $0.5 \mathrm{mg} / \mathrm{L}$ to $10 \mathrm{mg} / \mathrm{L}$. In each test, the solution $\mathrm{pH}$ was firstly adjusted to 5 or 8 , and then the FMBO was added into $500 \mathrm{~mL}$ solutions, in which the FMBO concentration was $0.12 \mathrm{mM}$ as Fe.

The competition effects of aqueous coexisting substances such as sulfate, bicarbonate, silicate and humic acid (expressed as DOC) on phosphate adsorption by FMBO were investigated. Tests were conducted in $500 \mathrm{~mL}$ of solutions containing phosphate concentration of $1.1 \mathrm{mg} / \mathrm{L}$ and coexisting substances of different concentrations. The concentrations of sodium sulfate and sodium bicarbonate varied from 0 to $5 \mathrm{mM}$. But as for sodium silicate and DOC, their concentrations were $0-0.5 \mathrm{mM}$ and $0-5.9 \mathrm{mg} / \mathrm{L}$, respectively. The solution $\mathrm{pH}$ was adjusted to 7 . Then the FMBO was added in $500 \mathrm{~mL}$ solutions for adsorption test and the iron concentration was $0.12 \mathrm{mM}$.

\subsection{Characterization}

The suspensions of different oxides were all freshly prepared prior to particle size determination and TEM observation. 

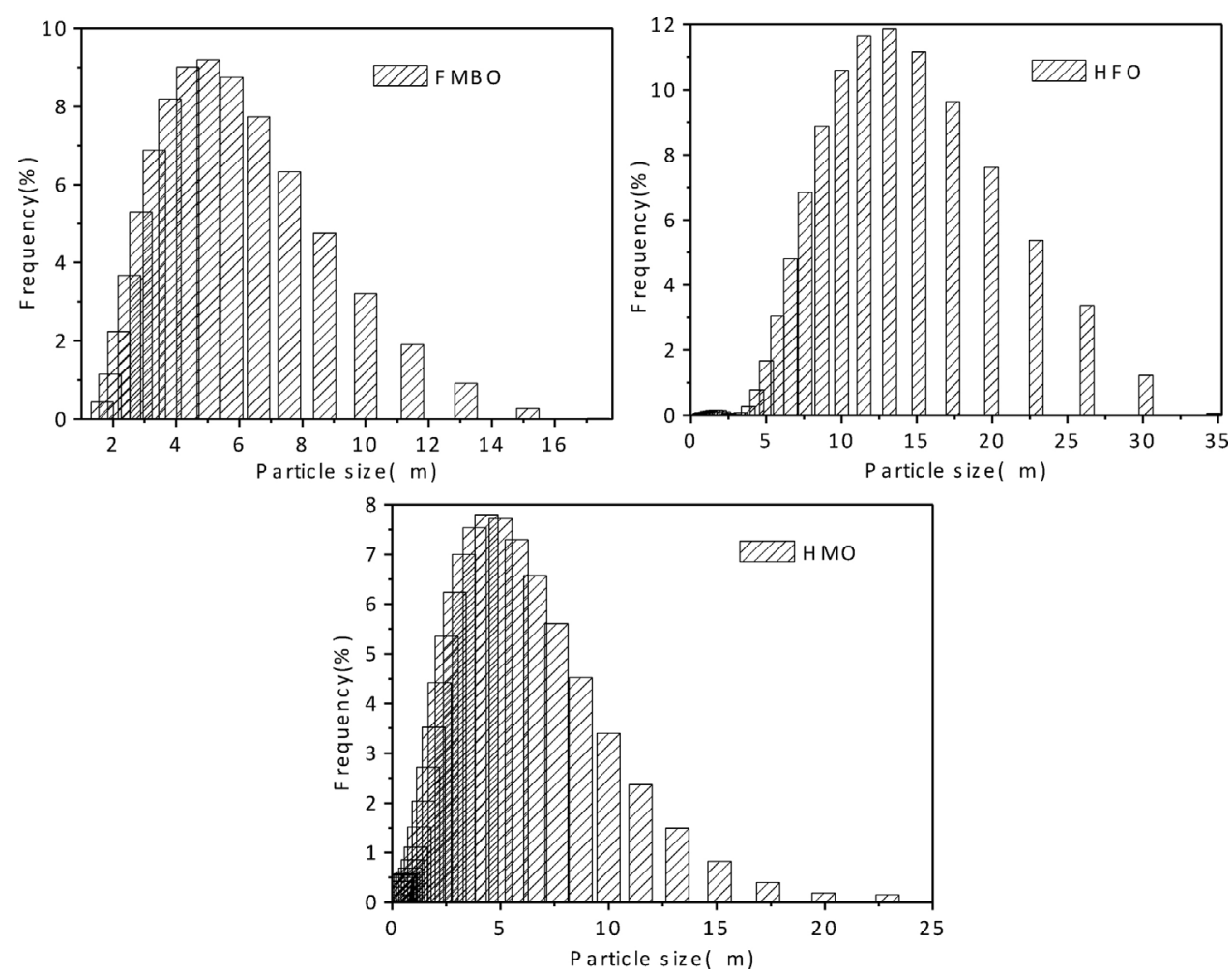

Fig. 1. Particle size distribution of FMBO, HFO and HMO.

Particle size distributions were measured by a laser particle size analyzer (Mastersizer 2000, Malvern Co., UK). The morphologies of different metal oxides were observed using a transmission electron microscopy (TEM, Hitachi H-7500, Japan). The FMBO samples before and after phosphate adsorption ( $\mathrm{pH} 7.0$ ) were collected and freeze-dried for FTIR analyses on a Tensor 27 FTIR spectrophotometer (Bruker Optics, Germany) under ambient conditions.

A Zetasizer 2000 analyzer (Malvern Co., UK) was used to measure the zeta potential of different oxides suspensions. As for the FMBO, HFO and FMMO suspensions, their concentrations were $1.2 \mathrm{mM}$ as Fe whereas the concentration of HMO suspension was $1.2 \mathrm{mM}$ as $\mathrm{Mn}$. The ionic strength of $0.01 \mathrm{M}$ was maintained with $\mathrm{NaCl}$. The zeta potential of FMBO suspension after phosphate adsorption was also analyzed for illuminating possible adsorption mechanism. All measurements of zeta potential were performed in triplicate and the average was used for data analyses.

Freeze-dried samples of FMBO, FMMO, HFO and HMO were analyzed using X-ray photoelectron spectroscopy (Kratos AXIS Ultra, $\mathrm{UK})$ with the monochromatic $\mathrm{Al} \mathrm{K} \alpha \mathrm{X}$-ray radiation $(1486.7 \mathrm{eV})$. The carbon peaks were used as an inner standard calibration peak at a binding energy of $284.8 \mathrm{eV}$. XPS data processing was performed using Vision (PR2.1.3) and CasaXPS (2.3.15) software. The specific surface area, pore diameter, and pore volume of freeze-dried samples were also measured using the Brunauer-Emmett-Teller (BET) method with a surface area analyzer (Micromeritics ASAP 2000, USA). XRD analysis of freeze-dried FMBO sample was performed on an X-ray powder diffractometer (X'Pert PRO MPD, PANalytical, Netherlands) with copper $K \alpha$ radiation. Surface element composition and overall metal contents of freeze-dried FMBO sample were also separately measured using a scanning electron microscope (SEM) with an EDAX KEVEX level 4 (Hitachi U3010, Japan) and acid digestion method.

\section{Results and discussion}

\subsection{Physicochemical properties of freshly formed oxides}

Phosphate adsorption on metal oxides was significantly affected by their morphologies. In this study, the particle size distribution curves of FMBO, HFO and HMO suspensions are shown in Fig. 1. It can be found that the main particle size of FMBO ranged from 2 to $15 \mu \mathrm{m}$, which was different from that of HFO and HMO. The main particle size of HFO and HMO was approximately in the range of 5-35 $\mu \mathrm{m}$ and $0-23 \mu \mathrm{m}$, respectively. The SEM image (Fig. 2) of FMBO revealed that there were many micropores on the FMBO surface. Moreover, binary oxide surfaces were rough and irregular in shape. The EDAX analysis showed that the percentages of Fe and $\mathrm{Mn}$ atoms were respectively $40.28 \%$ and $13.61 \%$ at the nearsurface of FMBO. This meant that Fe/Mn molar ratio was about 2.9. The TEM images of FMBO showed that the microparticles of FMBO appeared to have a nanostructure ranged in several tens of nanometers, and tiny particles aggregated together regularly. After phosphate adsorption, the nanostructure of FMBO microparticles was still visible while its shape became relatively irregular and the phosphate presumably covered the surface of FMBO.

The specific surface area, pore diameter and pore volume of these oxides are listed in Table S1. Obviously, in contrast to HFO, HMO and FMMO, FMBO has high specific surface area $\left(265 \mathrm{~m}^{2} / \mathrm{g}\right)$ and pore volume $\left(0.47 \mathrm{~cm}^{3} / \mathrm{g}\right)$. Further analyses of zeta potential of the oxide suspensions (Fig. 3) showed that with the exception of HMO whose $\mathrm{pH}_{\mathrm{ZPC}}$ ( $\mathrm{pH}$ of zero point of charge) was low at around 1.2 , the $\mathrm{pH}_{\mathrm{ZPC}}$ values of FMBO and FMMO approximated that of HFO, which were all higher than 7.0. Although the $\mathrm{pH}_{\mathrm{ZPC}}$ of HMO was very low, incorporation of manganese oxide into binary oxide did not reduce the $\mathrm{pH}_{\mathrm{ZPC}}$ of FMBO.

Other researchers also investigated the $\mathrm{pH}_{\mathrm{ZPC}}$ of binary oxides and obtained interesting results. Meng and Letterman [16] found 

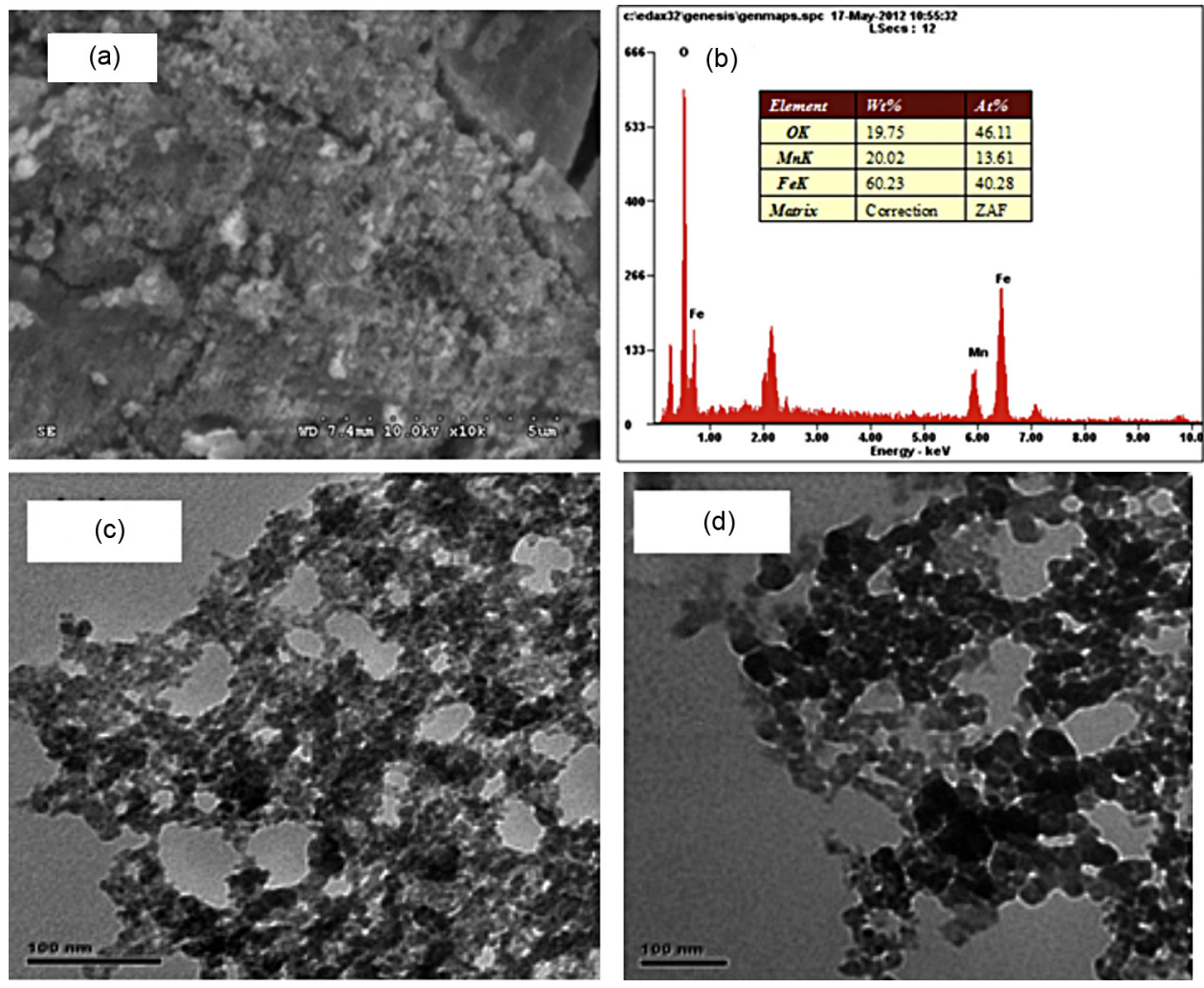

Fig. 2. (a) SEM image, (b) EDAX, (c) TEM image of FMBO and (d) TEM image of FMBO after phosphate adsorption (pH 7.0, 20 mg P/L).

that the $\mathrm{pH}_{\mathrm{ZPC}}$ of $\mathrm{Al}(\mathrm{OH})_{3} / \mathrm{SiO}_{2}$ suspension ( $4.5 \mathrm{mmol}-\mathrm{Al} / \mathrm{g}-\mathrm{SiO}_{2}$ ) was 9.1 same as that of pure $\mathrm{Al}(\mathrm{OH})_{3}$. Anderson and Benjamin [13] also observed that the $\mathrm{pH}_{\mathrm{ZPC}}$ of $\mathrm{Al}-\mathrm{Fe}$ binary oxide suspension approximated that of pure $\mathrm{Al}(\mathrm{OH})_{3}$. These studies indicate that in binary oxide systems, one oxide might prevail on binary oxide surfaces and strongly dominated the charge properties. In the current study, surface element measurement was further conducted using XPS analysis. The obtained result showed that the molar ratio of $\mathrm{Fe} / \mathrm{Mn}$ atoms at the near-surface of FMBO was 3.6, whereas its overall molar ratio of $\mathrm{Fe} / \mathrm{Mn}$ atoms in freeze-dried FMBO samples using acid digestion determination was only 2.3. The surface Fe/Mn molar ratios of FMBO obtained from XPS and EDAX analyses were both above its overall molar ratio. Further analyses of XRD patterns of FMBO, HFO and HMO (Fig. S1) revealed that the peak shape of FMBO was similar to that of HFO, which approximated that of the reported pure two-line ferrihydrite [17]. In another study on a Fe-Mn oxide adsorbent [17], it was suggested that most of the manganese atoms were incorporated in the bulk of the adsorbent and not at the surface, the surface mineralogy (XRD) and charge

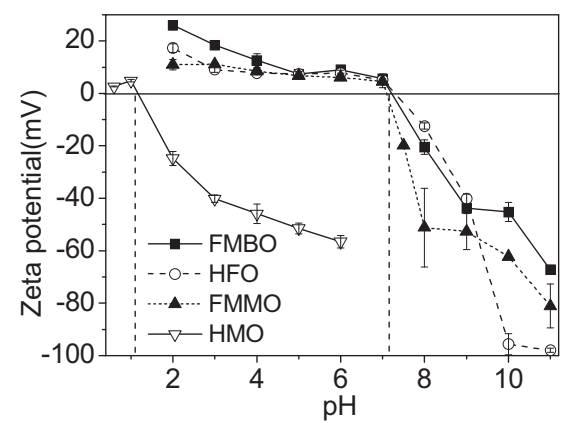

Fig. 3. Zeta potential of FMBO, HFO, FMMO and $\mathrm{HMO}$ at different $\mathrm{pH}$ values (FMBO, HFO and FMMO: [Fe] = 1.2 mM; HMO: $[\mathrm{Mn}]=1.2 \mathrm{mM}$ ). properties $\left(\mathrm{pH}_{\mathrm{ZPC}}\right)$ of the adsorbent were very close to those of the reported pure two-line ferrihydrite.

The above-mentioned discussions might suggest that as for the Fe-Mn binary oxide systems, ferric oxide was relatively enriched at the surface of FMBO, whereas manganese oxide was mostly incorporated into the bulk of FMBO. Therefore, the surface charge properties of FMBO were similar to hydrous ferric oxide. FMBO was not a simple mixture of HFO and HMO, and exhibited structures different from the simple component oxides.

\subsection{Adsorption studies}

\subsubsection{Effects of solution $p H$}

Solution $\mathrm{pH}$ is the most important factor that affects the adsorption process at the solid/liquid interface. Phosphate removal by different oxide systems as a function of solution $\mathrm{pH}$ was shown in Fig. 4. Over the $\mathrm{pH}$ range of 3-10, HMO exhibited low phosphate removals $(<16 \%)$. Since the $\mathrm{pH}_{\mathrm{ZPC}}$ of HMO was about 1.2 (Fig. 3 ), its surface was negatively charged at $\mathrm{pH} 3-10$, which resulted in its low removal for negatively charged phosphate ion. In contrast, FMBO, HFO and FMMO had significantly high phosphate removals. As the $\mathrm{pH}$ increased from 3 to 10, their phosphate removals generally tended to decrease. This may be associated with the speciation of phosphate and the surface charge of metal oxide. As shown in the speciation distribution diagrams of phosphate (Fig. S2), in the $\mathrm{pH}$ range of 2.1-7.2, the dominant species is $\mathrm{H}_{2} \mathrm{PO}_{4}{ }^{-}$, whereas between $\mathrm{pH} 7.2$ and 12.3, the main species is $\mathrm{HPO}_{4}{ }^{2-}$. Thus, higher $\mathrm{pH}$ led to more negatively charged phosphate species. Additionally, the surface charge of metal oxides is also $\mathrm{pH}$-dependent. At $\mathrm{pH}<\mathrm{pH}_{\mathrm{ZPC}}$, a positively charge surface prevails and it can strengthen the anionic phosphate adsorption on surfaces of metal oxides from the viewpoint of electrostatic attraction. However, when solution $\mathrm{pH}$ was above $\mathrm{pH}_{\mathrm{ZPC}}$, electrostatic repulsion should occur between metal oxides and phosphate ion. These two factors might result in the 
Table 1

Adsorption kinetics model parameters on FMBO, FMMO and HFO at pH 7.0.

\begin{tabular}{|c|c|c|c|c|c|c|}
\hline \multirow[t]{2}{*}{ Oxide } & \multirow{2}{*}{$\frac{\text { Pseudo-first-order model }}{q_{\mathrm{e}}(\mathrm{mol}-\mathrm{P} / \mathrm{mol}-\mathrm{Fe})}$} & \multicolumn{2}{|c|}{$\ln \left(q_{\mathrm{e}}-q_{\mathrm{t}}\right)=\ln q_{\mathrm{e}}-k_{1} t$} & \multirow{2}{*}{$\frac{\text { Pseudo-second-order model }}{q_{\mathrm{e}}(\mathrm{mol}-\mathrm{P} / \mathrm{mol}-\mathrm{Fe})}$} & \multicolumn{2}{|c|}{$t / q_{\mathrm{t}}=\left(1 / k_{2} q_{\mathrm{e}}^{2}\right)+\left(t / q_{\mathrm{e}}\right)$} \\
\hline & & $k_{1}\left(\min ^{-1}\right)$ & $R^{2}$ & & $k_{2}(\mathrm{~mol} / \mathrm{mol} \mathrm{min})$ & $R^{2}$ \\
\hline FMBO & 0.118 & 0.026 & 0.927 & 0.268 & 0.574 & 0.999 \\
\hline FMMO & 0.038 & 0.016 & 0.942 & 0.173 & 1.865 & 0.999 \\
\hline HFO & 0.031 & 0.015 & 0.932 & 0.150 & 2.240 & 0.999 \\
\hline
\end{tabular}

Table 2

Adsorption isotherms model parameters on FMBO at pH 5.0 and 8.0.

\begin{tabular}{|c|c|c|c|c|c|c|}
\hline & \multicolumn{3}{|l|}{ Langmuir } & \multicolumn{3}{|c|}{ Freundlich } \\
\hline & $q_{\mathrm{m}}(\mathrm{mol}-\mathrm{P} / \mathrm{mol}-\mathrm{Fe})$ & $b(\mathrm{~L} / \mathrm{mmol})$ & $R^{2}$ & $K_{\mathrm{F}}$ & $1 / n$ & $R^{2}$ \\
\hline pH 5.0 & 0.223 & $1.493 \times 10^{3}$ & 0.919 & 0.318 & 0.126 & 0.960 \\
\hline $\mathrm{pH} 8.0$ & 0.106 & $4.509 \times 10^{2}$ & 0.967 & 0.117 & 0.062 & 0.838 \\
\hline
\end{tabular}

decrease of phosphate removal with the increase of $\mathrm{pH}$. Interestingly, among these oxides, FMBO displayed the highest phosphate removal which decreased from $49 \%$ to $42 \%$ throughout the $\mathrm{pH}$ range of $3-10$. The high phosphate removal over a wide $\mathrm{pH}$ range is very favorable for the practical application of FMBO.

After phosphate adsorption, the zeta potentials of FMBO suspensions significantly decreased at different $\mathrm{pH}$ values as compared to those before adsorption (Fig. S3). Moreover, the $\mathrm{pH}_{\mathrm{ZPC}}$ of FMBO decreased to about 3.5. Generally, the specific adsorption of anions on metal oxides could result in more negative charge of the oxide surface and a decrease in the $\mathrm{pH}_{\mathrm{ZPC}}$ of metal oxides [18]. Above results indicated that specific adsorption and electrostatic interaction took place at the interface of aqueous phosphate and FMBO.

\subsubsection{Adsorption kinetics}

Since the phosphate adsorption on HMO was small, the adsorption kinetics experiments were further performed using FMBO, FMMO and HFO and the results were illustrated in Fig. 5. It was obvious that the adsorption process of phosphate on these three oxides could be divided into two steps, a fast step and a slow one. In the first 5 min, FMBO, FMMO and HFO respectively attained $71 \%, 84 \%$ and $85 \%$ of the maximum adsorption capacity and phosphate removal reached a maximum within about $60 \mathrm{~min}$. Then there was a slow adsorption process, which took a long time ( $>120 \mathrm{~min})$ to achieve equilibrium.

The kinetics data of phosphate adsorption onto these oxides were also fitted with the pseudo-first-order kinetic model and

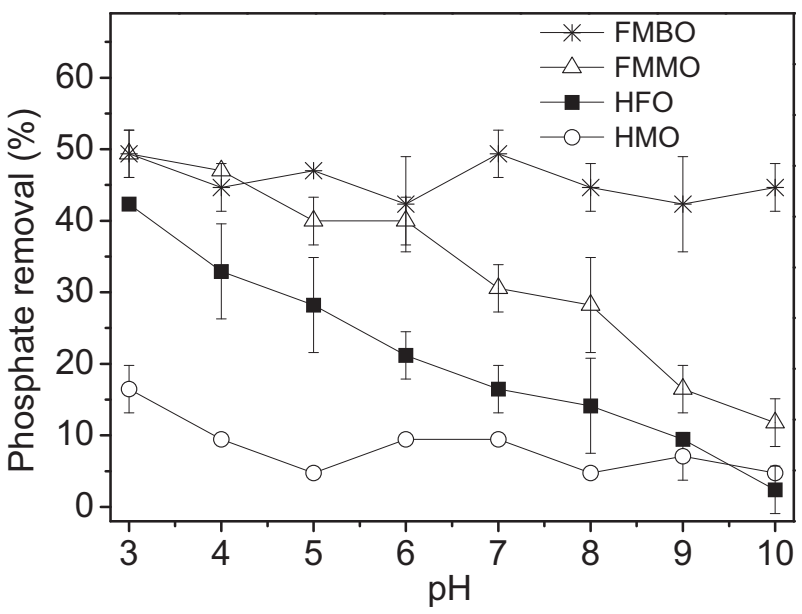

Fig. 4. Effects of solution $\mathrm{pH}$ on phosphate removal (for FMBO, HFO and FMMO $[\mathrm{Fe}]=0.12 \mathrm{mM}$; for HMO: $[\mathrm{Mn}]=0.12 \mathrm{mM}, 1.1 \mathrm{mg} \mathrm{P} / \mathrm{L}$ ) pseudo-second-order kinetic model (shown in Table S2), and calculated parameters were listed in Table 1 . By comparison of correlation coefficients $\left(R^{2}\right)$, it was evidently found that the fitness of the pseudo-second-order model was better than pseudofirst-order model for FMBO, FMMO and HFO (Fig. 5). This result indicates that chemisorption could be the dominant mechanism [19]. Furthermore, in terms of calculated pseudo-second-order rate constants $k_{2}$, the sequence was as follows: $k_{2}$ (FMBO) $<k_{2}$ $(\mathrm{FMMO})<k_{2}$ (HFO). It suggested that although the adsorption rate of FMBO was lower than HFO and FMMO, FMBO still displayed significantly higher adsorption capacity than FMMO and HFO. As has been demonstrated before, $\mathrm{FMBO}$ had a high $\mathrm{pH}_{\mathrm{ZPC}}$ and likely more active adsorption sites than FMMO and HFO, which enhanced the phosphate adsorption performance of FMBO.

\subsubsection{Adsorption isotherms}

Adsorption isotherms of phosphate on FMBO were further carried out at two different equilibrium pHs at $25^{\circ} \mathrm{C}$ (Fig. 6). It can be seen that with increasing phosphate concentrations the phosphate adsorption capacity increased gradually at $\mathrm{pH} 5.0$ and 8.0.

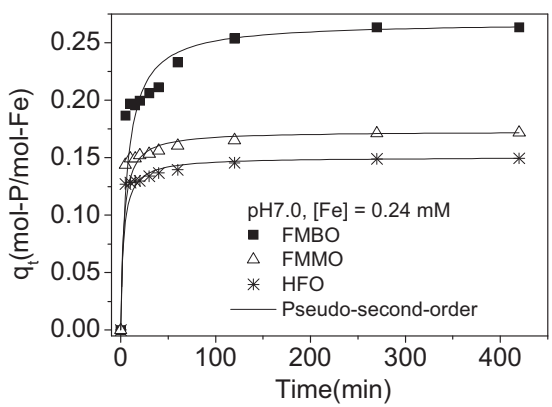

Fig. 5. Effect of reaction time on phosphate adsorption $(\mathrm{pH} 7.0,[\mathrm{Fe}]=0.24 \mathrm{mM}$ $2.6 \mathrm{mg} \mathrm{P} / \mathrm{L})$.

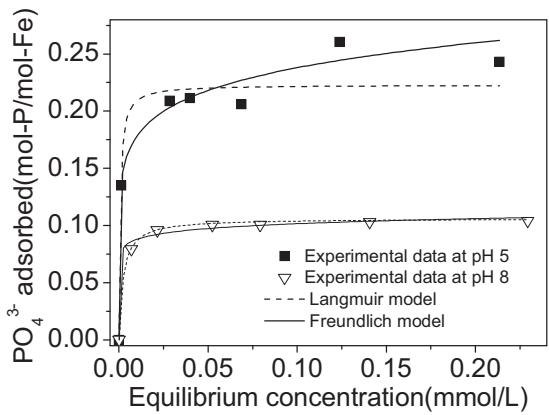

Fig. 6. Adsorption isotherms at different $\mathrm{pH}$ values ( $\mathrm{pH} 5.0$ or $8.0,[\mathrm{Fe}]=0.12 \mathrm{mM}$ ). 
Significantly, FMBO had a relatively high adsorption capacity at lower phosphate concentrations, which was favorable for the phosphate adsorption of low concentrations. The experimental data from adsorption isotherms were also modeled using the Langmuir and Freundlich isotherm equations (Table S3) and the calculated parameters were summarized in Table 2 . The maximum adsorption capacity obtained from Langmuir model $\left(q_{\mathrm{m}}\right)$ was about 0.223 and $0.106 \mathrm{~mol}-\mathrm{P} / \mathrm{mol}-\mathrm{Fe}$ at $\mathrm{pH} 5.0$ and 8.0, respectively. At $\mathrm{pH} 8.0$, the $q_{\mathrm{m}}$ was lower than that at $\mathrm{pH}$ 5.0. This is reasonable since the FMBO surface was deprotonated at $\mathrm{pH}>\mathrm{pH}_{\mathrm{ZPC}}$ (7.3). The deprotonation reaction could be written as: $\mathrm{M}-\mathrm{OH}+\mathrm{OH}^{-}=\mathrm{M}-\mathrm{O}^{-}+\mathrm{H}_{2} \mathrm{O}$, where the $\mathrm{M}-\mathrm{OH}$ represented the hydroxyl groups on the FMBO surfaces. So the phosphate adsorption capacity on the FMBO with negatively charged surfaces decreased, which had been discussed in detail in Section 3.2.1.

As can be seen from the correlation coefficients $\left(R^{2}\right)$, which could measure the goodness of fit, the two isotherm equations provided a good fit for phosphate adsorption on FMBO at pH 5.0 and 8.0. In general, the Langmuir equation only refers to the adsorption on homogeneous surfaces, whereas the Freundlich equation can be applied to the heterogeneous surface of adsorbents. In the current study, the incorporation of manganese oxide in the binary oxide might lead to a more heterogeneous surface of FMBO. Thus the Freundlich equation could be more suitable to describe the isotherm data.

\subsubsection{Effects of coexisting substances}

In aquatic systems, substances such as sulfate, bicarbonate, silicate or organic matters often co-occur with phosphate and accordingly compete with phosphate for adsorption sites on oxides. Within the range of usual concentrations in municipal water and wastewater, the effects of these coexisting substances on phosphate adsorption by FMBO at $\mathrm{pH} 7.0$ were investigated (Fig. 7). Apparently, sulfate just exhibited slight effect on phosphate removal, which only decreased from $48.4 \%$ to $47.5 \%$ with an increase in sulfate concentration from 0 to $5 \mathrm{mM}$. This result was consistent with other studies. Meng et al. [20] reported that sulfate had no remarkable effect on the removal of $\mathrm{As}(\mathrm{V})$ with ferric chloride at $\mathrm{pH}$ 6.8. It was attributable to the weaker affinity between sulfate and ferric hydroxide than that between $\mathrm{As}(\mathrm{V})$ and ferric hydroxide. Phosphate has also been considered to form innersphere complexes with metal hydroxides, whereas sulfate often was weakly bound with surface sites of metal hydroxides forming outer-sphere complexes, which led to ineffective competition of sulfate $[21,22]$.

As for bicarbonate and silicate, when their concentrations were raised from 0 to $5 \mathrm{mM}$ and $0.5 \mathrm{mM}$, the phosphate removal slightly lowered by $7.4 \%$ and $3.8 \%$, respectively. The effects of bicarbonate on oxyanions (e.g. phosphate and arsenate) on metal oxides were generally small $[22,23]$. The effects of silicate on anions adsorption were also reported by other researchers. Moöller and Sylvester [24] reported that high levels of silicate at $\mathrm{pH}$ above 8 had a detrimental effect on the arsenic removal by resin/iron oxide hybrid media. The results of Goh and Lim [25] implied that the adsorption of $\mathrm{As}(\mathrm{V})$ on nanocrystalline $\mathrm{Mg} / \mathrm{Al}$ layered double hydroxide decreased significantly when the molar ratio of silicate/arsenate increased from 0 to 100 at $\mathrm{pH} 8-11.5$. In general, silicate as a weak acid is not dissociated at $\mathrm{pH}<7$ according to its speciation distribution diagrams (Fig. S2), and it begins to dissociate at $\mathrm{pH} \geq 8$. Because neutral molecules generally have weak affinity for metal hydroxide surface [26], silicate showed little effect on phosphate adsorption under acidic or nearly neutral conditions. At $\mathrm{pH} \geq 8$, silicate gradually dissociates into $\mathrm{HSiO}_{3}{ }^{-}$and $\mathrm{SiO}_{3}{ }^{2-}$, these anions have greater affinity for metal hydroxide surface than neutral molecules, causing a stronger competition with phosphate.
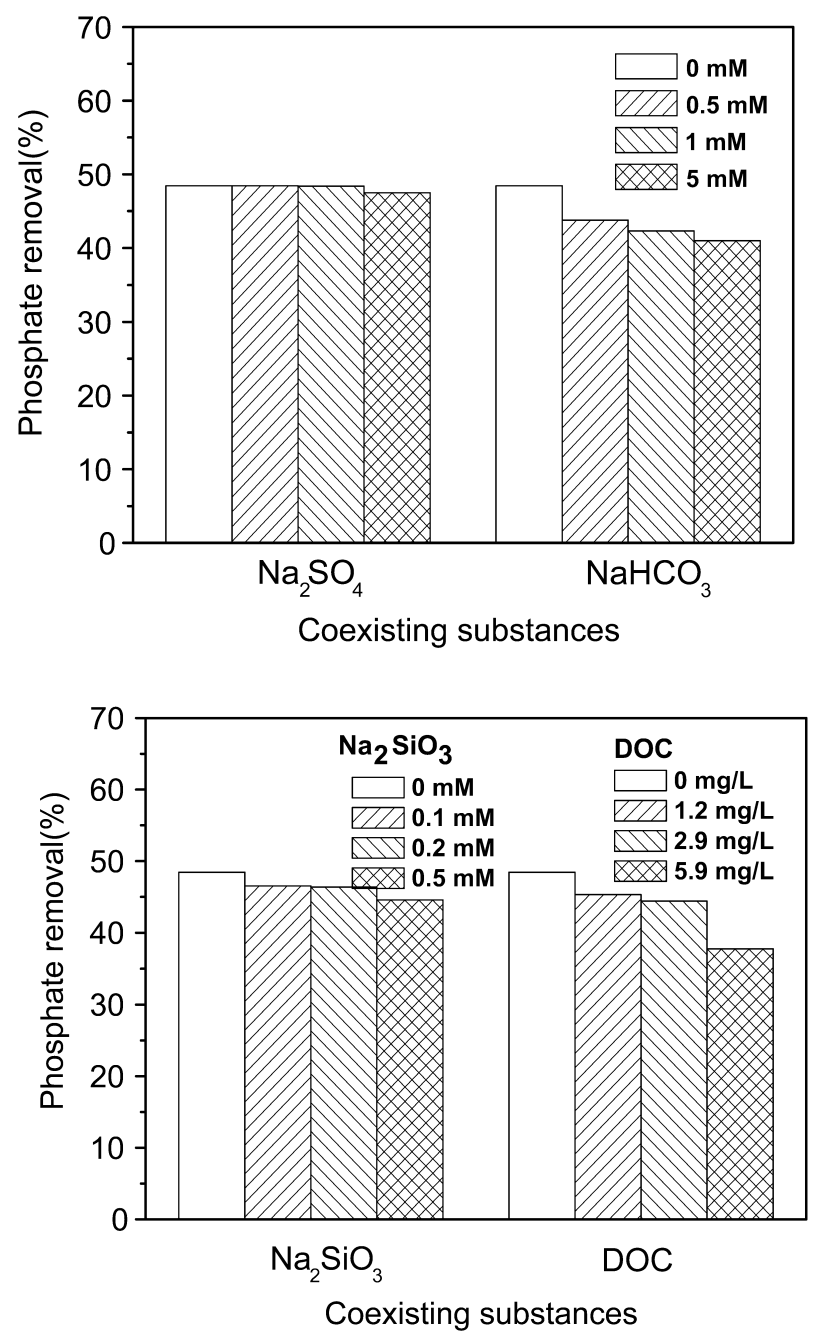

Fig. 7. Effect of coexisting substances on phosphate removal $(\mathrm{pH} 7.0,[\mathrm{Fe}]=0.12 \mathrm{mM}$, $1.1 \mathrm{mg} \mathrm{P} / \mathrm{L})$.

In comparison with sulfate, bicarbonate and silicate, DOC had a relatively distinct effect on phosphate removal, which resulted in its removal reduction from $48.4 \%$ to $37.7 \%$ with the rising of DOC concentration from $0 \mathrm{mg} / \mathrm{L}$ to $5.9 \mathrm{mg} / \mathrm{L}$. Many studies were carried out to investigate the effect of organic matters on adsorption by metal oxides surfaces and indicated that organic matters would compete for binding sites. In addition, some humic acid molecules specifically interacted with metal hydroxide surface, which resulted in the decrease of phosphate adsorption.

Overall, when the concentrations of these coexisting substances were in the range of normal concentrations, their effects on phosphate adsorption using FMBO were not significant, which was very favorable for the practical application of FMBO in water treatment under near-neutral $\mathrm{pH}$ condition.

\subsection{Phosphate removal mechanism by FMBO}

Spectral methods such as FTIR and XPS are often used to analyze the interaction mechanisms at the solid/liquid interface. The FTIR spectra of FMBO and phosphate-loaded FMBO at pH 7.0 are shown in Fig. 8. For all three samples, the broad band at $3430 \mathrm{~cm}^{-1}$ was assigned to the stretching vibrations of adsorbed water and the sharp band at $1630 \mathrm{~cm}^{-1}$ was assigned to the bending vibration of adsorbed water. The absorption band at $2360 \mathrm{~cm}^{-1}$ was common in all the three spectra which was assigned to the adsorbed 


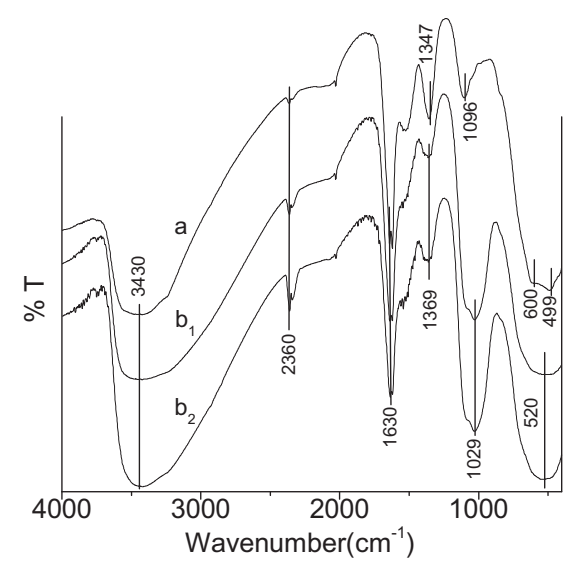

Fig. 8. FTIR spectra of FMBO (a) before and (b) after phosphate adsorption at different phosphate concentrations: $b_{1}=10 \mathrm{mg} \mathrm{P} / \mathrm{L}$ and $b_{2}=20 \mathrm{mg} \mathrm{P} / \mathrm{L}(\mathrm{pH} 7.0$, $[\mathrm{Fe}]=0.2 \mathrm{mM}$ )

carbonate, because the adsorption tests were carried out open to the atmosphere. The bands at 1347 and $1096 \mathrm{~cm}^{-1}$ in FMBO could be assigned to the bending vibration of hydroxyl groups of metal oxides (M-OH) [11], and the bands at 600 and $499 \mathrm{~cm}^{-1}$ could be ascribed to manganese oxide $\left(\mathrm{MnO}_{2}\right)$. Malankar et al. [27] pointed out that the absorption band of $\gamma-\mathrm{MnO}_{2}$ was in the range $600-400 \mathrm{~cm}^{-1}$. Li et al. [28] assigned the band at around $523 \mathrm{~cm}^{-1}$ to the $\mathrm{Mn}-\mathrm{O}$ vibrations of $\mathrm{MnO}_{6}$ octahedron of $\alpha-\mathrm{MnO}_{2}$.

After phosphate adsorption, the disappearance of bands at 600 and $499 \mathrm{~cm}^{-1}$ was observed and a new peak appeared at $520 \mathrm{~cm}^{-1}$. It indicates that the manganese oxide in FMBO was also involved in phosphate adsorption as confirmed by $\mathrm{pH}$ effect tests. The $\mathrm{M}-\mathrm{OH}$ bands at 1347 and $1096 \mathrm{~cm}^{-1}$ disappeared completely while two new bands appeared at 1369 and $1029 \mathrm{~cm}^{-1}$ attributed to the asymmetry vibration of $\mathrm{P}-\mathrm{O}$ [29]. Moreover, the intensity of the two bands increased gradually with the increase of phosphate concentration. Above analyses could imply the complex reaction of surface hydroxyl groups with aqueous phosphate.

To further explore adsorption mechanism of phosphate on the FMBO, XPS spectra of the FMBO and phosphate-loaded FMBO were also analyzed. Based on the binding energy of different oxygen species, the $01 \mathrm{~s}$ XPS spectra were divided into two peaks corresponding to $\mathrm{M}-\underline{\mathrm{O}}$ (oxygen bonded to metal) and $\mathrm{M}-\underline{\mathrm{OH}}$ (hydroxyl bonded to metal) (Fig. 9) [12]. For the FMBO, the percentages of $\mathrm{M}-\underline{\mathrm{O}}(529.7 \mathrm{eV})$ and $\mathrm{M}-\underline{\mathrm{OH}}(531.0 \mathrm{eV})$ were respectively $26.0 \%$ and $74.0 \%$. After phosphate adsorption, the percentage of $\mathrm{M}-\underline{\mathrm{O}}$ $(530.1 \mathrm{eV})$ increased from $26.0 \%$ to $37.0 \%$, while the percentage of $\mathrm{M}-\mathrm{OH}\left(531.5 \mathrm{eV}\right.$ ) reduced to $63.0 \%$. Since $\mathrm{H}_{2} \mathrm{PO}_{4}{ }^{-}$and $\mathrm{HPO}_{4}{ }^{2-}$ are the dominant phosphate species at $\mathrm{pH} 7.0$, one or two $\mathrm{P}-\mathrm{OH}$ groups are present in one phosphate molecule. Thus, phosphate adsorption on the FMBO should increase the percentage of $\mathrm{M}-\mathrm{OH}$ if no hydroxyl groups on the metal oxide disappear in the adsorption process. The obvious decrease of $\mathrm{M}-\mathrm{OH}(531.5 \mathrm{eV})$ percentage on the phosphate-loaded FMBO surface was observed and further proved that the $\mathrm{M}-\underline{\mathrm{OH}}$ was involved in the phosphate adsorption, which was consistent with the results of FTIR.

On the basis of aforementioned zeta potential, FTIR and XPS analyses, it can be inferred that at $\mathrm{pH} 7.0$, since the solution $\mathrm{pH}$ was below the $\mathrm{pH}_{\mathrm{ZPC}}$ (7.3), some hydroxyl groups would be positively charged due to protonation, and they could adsorb electronegative phosphate through electrostatic attraction. On the other hand, phosphate could be specifically adsorbed on the FMBO surface via the formation of monodentate and bidentate inner-sphere surface complexes. According to the configuration reactions of innersphere surface complex (Fig. S4), the stoichiometric ratio of surface hydroxyl between the original oxide and the phosphate-loaded
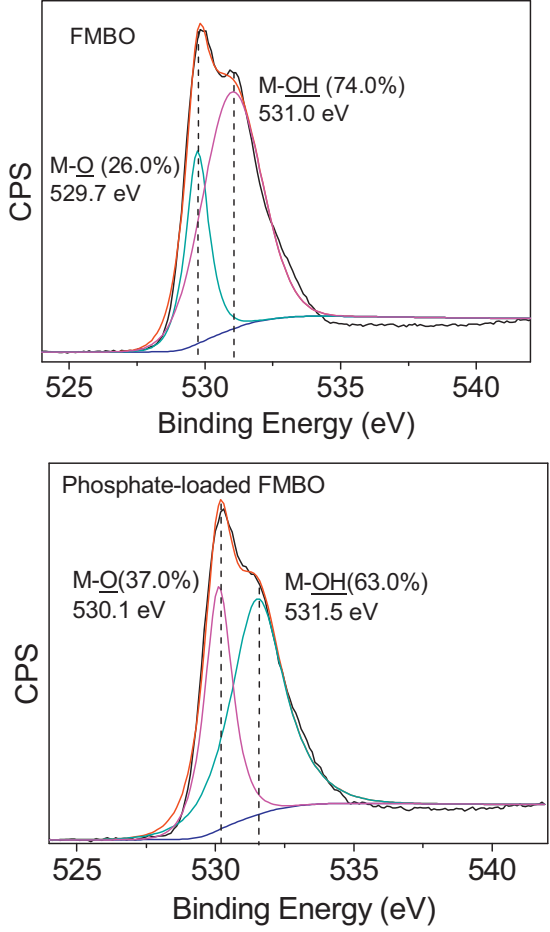

Fig. 9. O 1s XPS spectra of FMBO before and after phosphate adsorption (pH 7.0, [Fe $]=0.2 \mathrm{mM}, 20 \mathrm{mg} \mathrm{P} / \mathrm{L}$ ).

oxide was 0.5 for a monodentate complex and 2 for a bidentate complex. In the present study, the ratio of surface hydroxyl in the FMBO (74.0\%) to the phosphate-loaded FMBO (63.0\%) was about 1.2 , which could indicate that monodentate and bidentate complexes could be formed when phosphate was adsorbed on the surface of FMBO.

\section{Conclusions}

Freshly formed FMBO suspension synthesized by the oxidation and coprecipitation method exhibited the highest selective adsorption capability towards phosphate as compared to FMMO and their simple oxide (i.e., HFO and HMO). The surfaces of FMBO were found to be rough and nanostructured. Zeta potential, XRD, EDAX and XPS analyses showed that ferric oxide was enriched on the surface of binary oxide, resulting in the surface mineralogy (XRD) and charge properties of FMBO microparticles similar to hydrous ferric oxide.

Adsorption kinetics data showed that pseudo-second-order model provided a better fit for phosphate adsorption by FMBO. At pH 5.0, the estimated Langmuir adsorption capacity was 0.223 mol$\mathrm{P} / \mathrm{mol}-\mathrm{Fe}$. At neutral $\mathrm{pH}$, the competition effects of coexisting substances such as sulfate, bicarbonate, silicate and DOC on phosphate adsorption using FMBO were not significant. The results of zeta potential, FTIR and XPS analyses indicated that at $\mathrm{pH}$ 7.0 , besides electrostatic attraction, the replacement of surface hydroxyl groups $(\mathrm{M}-\mathrm{OH})$ played a great role in phosphate adsorption on the FMBO via formation of monodentate and bidentate complexes on its surface. Compared with powdered adsorbents, freshly formed FMBO shows excellent application potentials to be prepared in situ and dosed in water treatment process, especially for the remediation of phosphate-contaminated water body. Currently, the pilot-scale experiments using freshly formed FMBO as adsorbents are being conducted in depth by our research group. 


\section{Acknowledgments}

This study was funded by the National Science Foundation for Distinguished Young Scholars of China (No. 51225805), the National Natural Science Foundation of China (Nos. 51108298 and 51138009 ) and the Natural Science Foundation of Tianjin (No. 12JCYBJC14800). The authors also acknowledge the financial support from the Research Fund of Tianjin Key Laboratory of Aquatic Science and Technology (No. TJKLAST-2011-13).

\section{Appendix A. Supplementary data}

Supplementary data associated with this article can be found, in the online version, at http://dx.doi.org/10.1016/j.colsurfa. 2014.04.034.

\section{References}

[1] M.R. Awual, A. Jyo, T. Ihara, N. Seko, M. Tamada, K.T. Lim, Enhanced trace phosphate removal from water by zirconium(IV) loaded fibrous adsorbent, Water Res. 45 (2011) 4592-4600.

[2] T.H. Boyer, A. Persaud, P. Banerjee, P. Palomino, Comparison of low-cost and engineered materials for phosphorus removal from organic-rich surface water, Water Res. 45 (2011) 4803-4814.

[3] I. Vicente, P. Huang, F.Ø. Andersen, H.S. Jensen, Phosphate adsorption by fresh and aged aluminum hydroxide: consequences for lake restoration, Environ. Sci. Technol. 42 (2008) 6650-6655.

[4] P. Delaney, C. McManamon, J.P. Hanrahan, M.P. Copley, J.D. Holmes, M.A. Morris, Development of chemically engineered porous metal oxides for phosphate removal, J. Hazard. Mater. 185 (2011) 382-391.

[5] D.E. Giles, M. Mohapatra, T.B. Issa, S. Anand, P. Singh, Iron and aluminium based adsorption strategies for removing arsenic from water, J. Environ. Manag. 92 (2011) 3011-3022.

[6] M. Waseem, S. Mustafa, A. Naeem, G.J.M. Koper, K.H. Shah, $\mathrm{Cd}^{2+}$ sorption characteristics of iron coated silica, Desalination 277 (2011) 221-226.

[7] Y.T. Liu, D. Hesterberg, Phosphate bonding on noncrystalline Al/Fe-hydroxide coprecipitates, Environ. Sci. Technol. 45 (2011) 6283-6289.

[8] G.S. Zhang, H.J. Liu, R.P. Liu, J.H. Qu, Removal of phosphate from water by a Fe-Mn binary oxide adsorbent, J. Colloid Interface Sci. 335 (2009) 168-174.

[9] Y.Zhang, M. Yang, X.M. Dou, H. He, D.S. Wang, Arsenate adsorption on an Fe-Ce bimetal oxide adsorbent: role of surface properties, Environ. Sci. Technol. 39 (2005) 7246-7253.

[10] K. Gupta, U.C. Ghosh, Arsenic removal using hydrous nanostructure iron(III)-titanium(IV) binary mixed oxide from aqueous solution, J. Hazard. Mater. 161 (2009) 884-892.
[11] K. Biswas, K. Gupta, A. Goswami, U.C. Ghosh, Fluoride removal efficiency from aqueous solution by synthetic iron(III)-aluminum(III)-chromium(III) ternary mixed oxide, Desalination 255 (2010) 44-51.

[12] S.B. Deng, H. Liu, W. Zhou, J. Huang, G. Yu, Mn-Ce oxide as a high-capacity adsorbent for fluoride removal from water, J. Hazard. Mater. 186 (2011) 1360-1366.

[13] P.R. Anderson, M.M. Benjamin, Surface and bulk characteristics of binary oxide suspensions, Environ. Sci. Technol. 24 (1990) 692-698.

[14] R.P. Liu, W.X. Gong, H.C. Lan, Y.P. Gao, H.J. Liu, J.H. Qu, Defluoridation by freshly prepared aluminum hydroxides, Chem. Eng. J. 175 (2011) 144-149.

[15] S. Mustafa, M.I. Zaman, S. Khan, Temperature effect on the mechanism of phosphate anions sorption by $\beta-\mathrm{MnO}_{2}$, Chem. Eng. J. 141 (2008) 51-57.

[16] X.G. Meng, R.D. Letterman, Effect of component oxide interaction on the adsorption properties of mixed oxides, Environ. Sci. Technol. 27 (1993) 970-975.

[17] H. Zeng, B. Fisher, D.E. Giammar, Individual and competitive adsorption of arsenate and phosphate to a high-surface-area iron oxide-based sorbent, Environ. Sci. Technol. 42 (2008) 147-152.

[18] W. Stumm, J.J. Morgan, Aquatic Chemistry: Chemical Equilibria and Rates in Natural Waters, third ed., Wiley-Interscience, New York, 1996.

[19] G. Sposito, The Surface Chemistry of Soils, Oxford University Press, New York 1984.

[20] X.G. Meng, S. Bang, G.P. Korfiatis, Effects of silicate, sulfate, and carbonate on arsenic removal by ferric chloride, Water Res. 34 (2000) 1255-1261.

[21] N. Zhang, L.S. Lin, D.C. Gang, Adsorptive selenite removal from water using iron-coated GAC adsorbents, Water Res. 42 (2008) 3809-3816.

[22] B.J. Pan, J. Wu, B.C. Pan, L. Lv, W.M. Zhang, L.L. Xiao, X.S. Wang, X.C. Tao S.R. Zheng, Development of polymer-based nanosized hydrated ferric oxides (HFOs) for enhanced phosphate removal from waste effluents, Water Res. 43 (2009) 4421-4429.

[23] Y. Arai, D.L. Sparks, J.A. Davis, Effects of dissolved carbonate on arsenate adsorption and surface speciation at the hematite-water interface, Environ. Sci. Technol. 38 (2004) 817-824.

[24] T. Moöller, P. Sylvester, Effect of silica and pH on arsenic uptake by resin/iron oxide hybrid media, Water Res. 42 (2008) 1760-1766.

[25] K.H. Goh, T.T. Lim, Influences of co-existing species on the sorption of toxic oxyanions from aqueous solution by nanocrystalline $\mathrm{Mg} / \mathrm{Al}$ layered double hydroxide, J. Hazard. Mater. 180 (2010) 401-408.

[26] X.H. Guan, H.R. Dong, J. Ma, L. Jiang, Removal of arsenic from water: effects of competing anions on As(III) removal in $\mathrm{KMnO}_{4}$-Fe(II) process, Water Res. 43 (2009) 3891-3899.

[27] H. Malankar, S.S. Umare, K. Singh, M. Sharma, Chemical composition and discharge characteristics of $\gamma-\mathrm{MnO}_{2}$ prepared using manganese ore, J. Solid State Electrochem. 14 (2010) 71-82.

[28] X.J. Li, C.S. Liu, F.B. Li, Y.T. Li, L.J. Zhang, C.P. Liu, Y.Z. Zhou, The oxidative transformation of sodium arsenite at the interface of $\alpha-\mathrm{MnO}_{2}$ and water, J. Hazard. Mater. 173 (2010) 675-681.

[29] P. Persson, N. Nilsson, S. Sjöberg, Structure and bonding of orthophosphate ions at the iron oxide-aqueous interface, J. Colloid Interface Sci. 177 (1996) $263-275$. 